\title{
Measures for controlling the material flow when extruding sheet-bulk metal forming parts from coil
}

\author{
Johannes Henneberg* and Marion Merklein \\ Institute of Manufacturing Technology, Friedrich-Alexander-Universität Erlangen-Nürnberg, Egerlandstraße 13, \\ 91058 Erlangen, Germany
}

Received: 18 August 2020 / Accepted: 19 September 2020

\begin{abstract}
The increasing demand for lightweight design requires functional integration. This poses challenges to conventional manufacturing processes due to the rising geometrical complexity of components. The application of bulk forming operations to sheet metal, named sheet-bulk metal forming (SBMF), is one approach to overcome these challenges. Currently, mainly pre-cut blanks are applied in research of SBMF. Production from coil, in contrast, would combine the advantages of SBMF with the advantages of manufacturing from a coil regarding high output quantity. To research SBMF from coil, a lateral and a backward extrusion process are set up. In addition to a reduced geometrical accuracy of the parts, which is known from SBMF of pre-cut blanks, an anisotropic material flow is identified as a coil-specific challenge. The aim of this research is to investigate measures that extend the forming limits by means of a material flow control. For this purpose, a combined numerical-experimental approach is applied in order to analyze and evaluate an adaption of the width of the coil, the feed width, and the local friction as measures for material flow control. Particularly local adaptation of friction by means of modified tool surfaces reduces the anisotropic material flow and improves the geometrical accuracy of the parts.
\end{abstract}

Keywords: Extrusion / sheet metal / cold forming / sheet-bulk metal forming / material flow control

\section{Introduction}

The increasing demand for lightweight construction, for example in transportation engineering [1], confronts production technology with the challenge to reduce the system weight. One approach to meet this challenge is component design with functional integration [2]. This approach achieves the aim of lightweight construction by reducing the weight of the system [2]. Due to the resulting increase in geometrical complexity of the components, conventional forming processes reach their limits [3]. This motivates research of the process class of sheet-bulk metal forming (SBMF). By applying bulk forming operations to sheet metal, often in combination with a sheet metal forming operation, functional elements are formed by a three-dimensional material flow [4]. Stimulated by the importance of SBMF for the manufacturing of functionally integrated components, the process class is subject of numerous investigations. Similar processes are researched under the terms plate forging [5], flow control forming [6]

\footnotetext{
* e-mail: johannes.henneberg@fau.de
}

and local metal sheet thickening [7]. The production of powertrain components such as duplex gears [8], geared drums [9], or gear wheels for combustion engines [10] is being investigated. In order to ensure a sufficient flexibility of the material supply, pre-cut blanks are often used [11]. In comparison, production from a coil instead of pre-cut blanks would have the advantage of shorter cycle times and thus higher output [12]. The reason for this is the faster transport of parts between forming stages due to the coil connection and the associated elimination of cycle-timelimiting handling systems. Consequently, this type of forming is an efficient approach for the production of large quantities of high-quality components [13]. Since SBMF parts like components of the powertrain are often required in high quantities, a production from coil would have a high potential. There are industrial approaches to produce components from coil by SBMF, such as the forming of headphone yokes [6] or duplex gears [14]. Tajul et al. identified an anisotropic material flow as a major challenge in incremental forming of coil sections [15]. In addition, in SBMF of pre-cut blanks, a reduced geometrical accuracy of the components as a result of a partially uncontrolled material flow is another challenge [11]. In this context, 


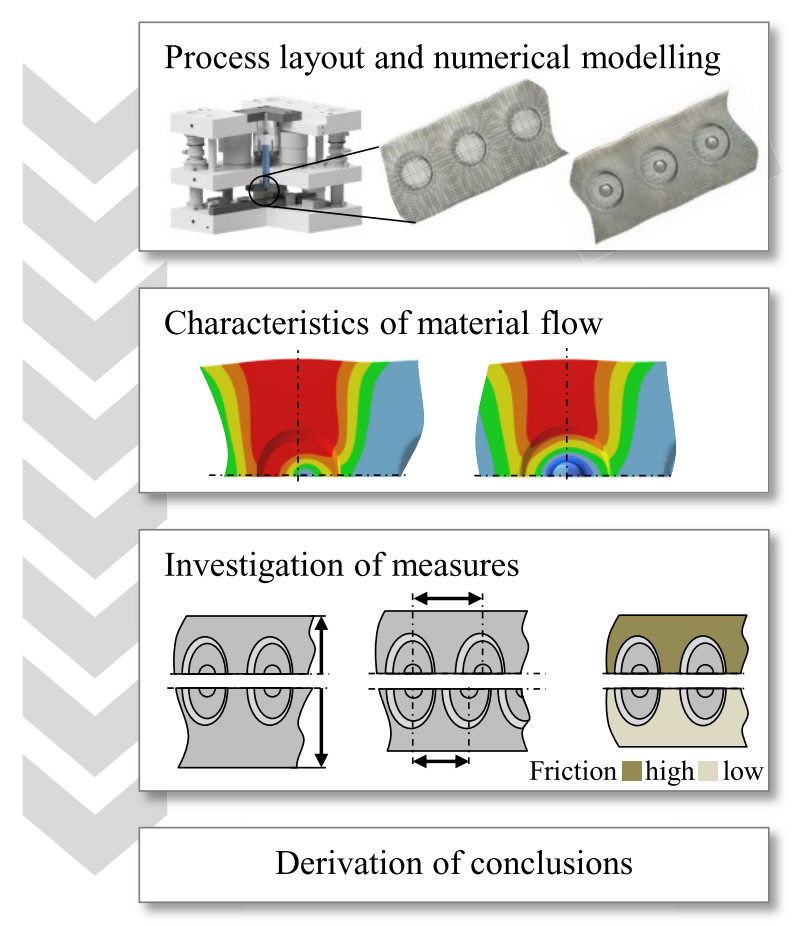

Fig. 1. Methodology.

measures to improve the part accuracy by a material flow control are to be investigated to benefit from the advantages of SBMF of parts from coil.

\section{Objective and methodology}

The objective of the presented research is to create a fundamental understanding of measures for improving the geometrical accuracy of components produced by SBMFprocesses from coil by means of a material flow control. This requires the identification of cause-effect relations of the different measures. In addition, the transferability of material flow controlling modifications, which are known from the SBMF of pre-cut blanks, has to be examined. Finally, different approaches are to be evaluated regarding their effectiveness and practicability in order to provide recommendations for measures for extending the forming limits when SBMF parts from coil. To achieve these objectives, the methodology shown in Figure 1 is applied.

In a first step, two extrusion processes for the SBMF of components from coils are designed as a basis for research. In addition to the experimental setup of the processes, they are mapped by virtual process models. The simulation models, validated by comparison with the experiments, are necessary for the research of the processes without costly experiments and the investigation of target values that experimentally can only be analyzed to a limited extent. As a basis for investigation of measures to overcome the forming limits, the characteristics and causes of the material flow are examined in both processes. Based on this, requirements for measures will be derived. Subsequently, workpiece-, process- and tool-sided approaches are numerically examined with regard to their suitability to influence the component geometry. Suitable variants of the

\section{Backward extrusion Lateral extrusion}

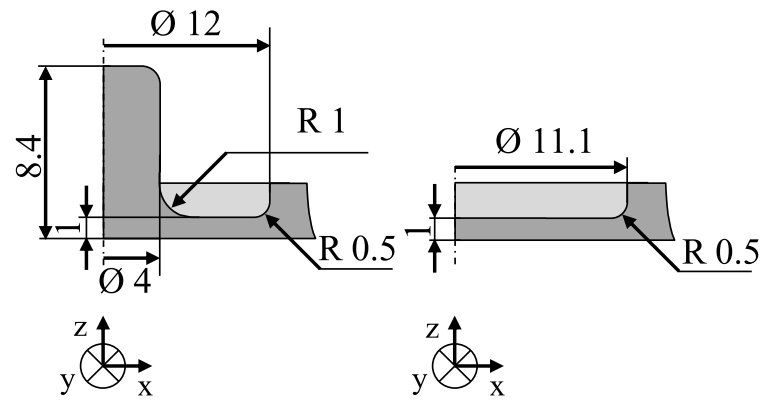

Fig. 2. Part geometry in backward and lateral extrusion.

measures are implemented experimentally to verify the numerical findings. Finally, the results regarding the measures are synthesized as well as evaluated, and recommendations for a material flow control in SBMF of parts from coil are concluded.

\section{Process layout}

\subsection{Process setup}

For the design of the processes, general and workpiece specific requirements are defined. General requirements are, firstly, a transferability of the results. Therefore, a lateral as well as a backward extrusion process are set up to ensure transferability of the findings regarding different main material flow directions. In addition, comparability of the results between the processes is targeted. Therefore, the same material volume is formed in both processes and equal resulting sheet thicknesses are aimed for. A central objective of SBMF is to shorten the process chains [5]. For this reason, the components are to be formed in a single stroke. In order to benefit from the advantages of a production from coil, high output quantities have to be achieved. Thus, the requirements are short cycle times and a long tool life. This is ensured by designing the tools according to [16] as well as by implementing the processes on a high-speed press.

A component-specific requirement is that the material usage per part must be minimized. This ensures that the tools are capable of material-efficient tool life research in future investigations. Furthermore, the components must be similar to the parts produced through established SBMF processes. The functional elements manufactured by SBMF are of a similar size as the sheet thickness [17]. On the one hand, a pin is produced by backward extrusion. Pins are important design elements in electrical and automotive industries [18]. The forming of these elements from pre-cut blanks by SBMF processes is researched in [19]. On the other hand, a blind cavity is formed by lateral extrusion. Both functional elements - pin and blind cavity - are widely used in SBMF as positioning and stop elements or for material pre-distribution [20]. Schlagau et al., for example, present a process in which both functional elements are produced in combination for the manufacturing of planetary gear carriers from coil [21]. The geometries shown in Figure 2 are deducted from the requirements. 


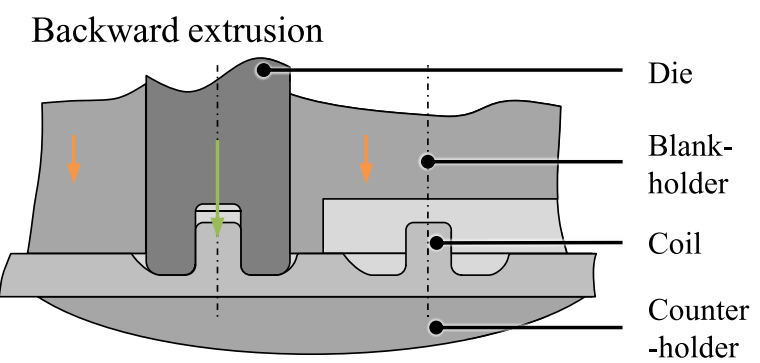

Lateral extrusion

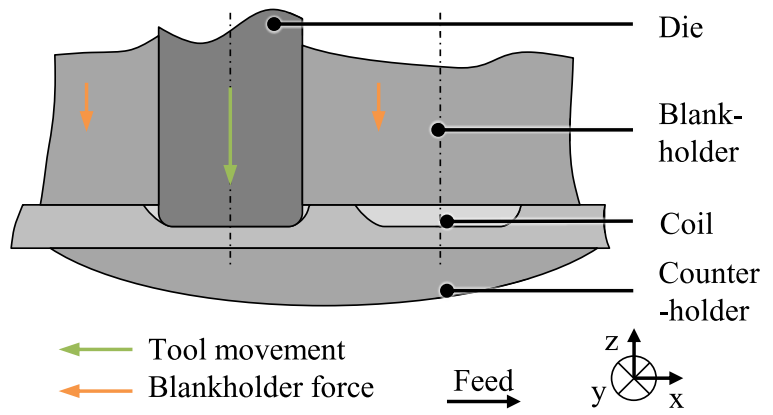

Fig. 3. Tool systems and process kinematics in backward and lateral extrusion.

Since there are studies on the influence of the pin geometry - produced by backward [20] and forward extrusion [22] - on the process results, the following section does not focus on this. A pin with a diameter of $4 \mathrm{~mm}$ is produced by backward extrusion, forming the coil up to a resulting sheet thickness of $1.0 \mathrm{~mm}$. A die with an outer diameter of $12.0 \mathrm{~mm}$ is applied for this purpose. To reduce load maxima, the die has an outer edge radius of $0.5 \mathrm{~mm}$ and an inner one of $1.0 \mathrm{~mm}$. A complete material flow of the displaced material into the die cavity would result in a pin height of $8.4 \mathrm{~mm}$. The blind cavity is formed by lateral extrusion, once more up to a resulting sheet thickness of $1.0 \mathrm{~mm}$. In order to displace the same material volume in both processes, the blind cavity has a targeted diameter of $11.1 \mathrm{~mm}$ and an edge radius of $0.5 \mathrm{~mm}$. The workpiece material used in both processes is the mild deep-drawing steel 1.0338 due to its established usage in SBMF [23] with an initial sheet thickness of $2 \mathrm{~mm}$ and a coil width of $30 \mathrm{~mm}$. The geometries of the active tool parts are derived from the components and used in the tool systems shown in Figure 3.

In both processes, the tool system consists of a die, a blankholder, and a counterholder. In a first step, the coil is fixed by the blankholder driven by gas pressure springs with a force of $130 \mathrm{kN}$. This results in a contact pressure of approximately $65 \mathrm{MPa}$, which is characteristic for SBMF processes [11] and prevents the coil from thickening in the area adjacent to the functional elements. In a next step, the components are formed by the downward moving dies. To reduce high tribological loads, the workpieces are lubricated with Beruforge 150 DL. Afterwards, the dies move back to demold the parts. Lifting of the coil during demolding is prevented by the blankholder. In the following step, the blankholder releases the components, which are moved out of the forming zone by a feed of $20 \mathrm{~mm}$. For the next forming operation, the feed provides a new coil section.

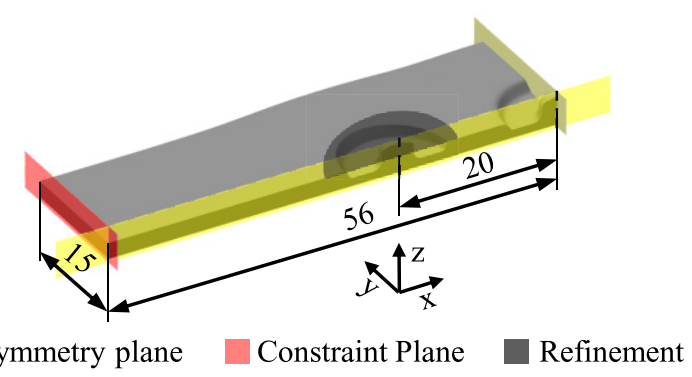

Fig. 4. Workpiece geometry in the simulation of the backward extrusion process.

By applying the described tool systems on the high-speed press BSTA 510-10125B2 from Bruderer AG, 100 components per minute can be produced. Consequently, the advantage of a production from coil regarding high output quantities is used.

\subsection{Numerical process modelling and validation}

The application of the finite element method is established in metal forming for a process analysis and the development of process understanding [24]. In the context of the presented research, simulations are utilized to investigate the material flow as well as material flow-controlling measures.

\subsubsection{Model setup}

For the virtual process models, the program Simufact. forming 14 is applied. The suitability of this software for the mapping of SBMF processes was shown in [11]. For the representation of the tribology, a friction factor of 0.1 is chosen. In [25] it was shown that this friction factor is appropriate for mapping friction during extrusion of sheet metal with the applied tribological system. In order to reduce the high computational time while keeping the level of findings constant, the symmetry of the processes on the $\mathrm{X}$-axis is used in both models. A $180^{\circ}$ segment of the components is simulated according to Figure 4.

To ensure stable simulation models, the tools are modeled rigidly in accordance to [11]. Both, the tool design and the process kinematics correspond to Figure 3. The blankholder tension is represented by a compressed spring with a low stiffness of $10^{-6} \mathrm{~N} / \mathrm{mm}$. By that, an approximately constant force independent of the deflection of the spring is ensured. The mechanical properties of the workpiece material 1.0338 are modelled by a flow curve, that is determined experimentally in a layer compression test at room temperature following DIN 50106 [26] up to a true strain of $\varphi=0.57$. The initial true stress is $180 \mathrm{MPa}$. Since higher true strains are to be expected in SBMF [11], the flow curve is extrapolated according to the HockettSherby approach [27] up to a true strain of $\varphi=4.00$. For the material flow simulation, the parts must be discretized. According to [28], the parts are meshed hexagonally. A maximum edge length of $0.3 \mathrm{~mm}$ is selected. To improve the simulation's accuracy, the forming zones are meshed in a cylindrical area around the center of the parts with 


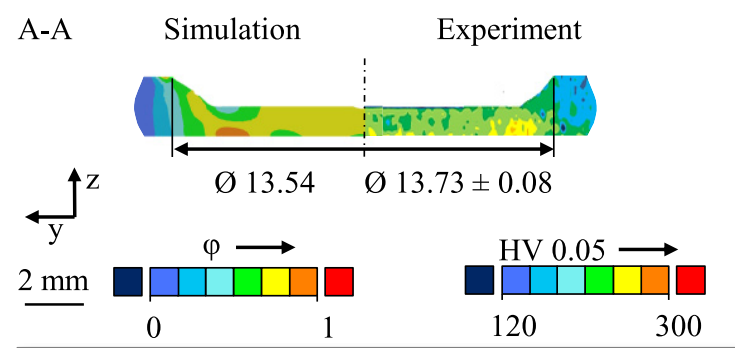

Lateral extrusion: Part geometry

Material 1.0338 Lubricant BF150DL

$\mathrm{n}_{\text {Specimen }} 5$

Hardness HM2000

Geometry VHX-100K

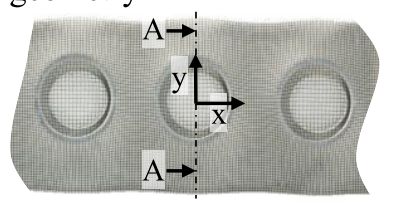

Fig. 5. Comparison of numerically and experimentally evaluated component properties in lateral extrusion.

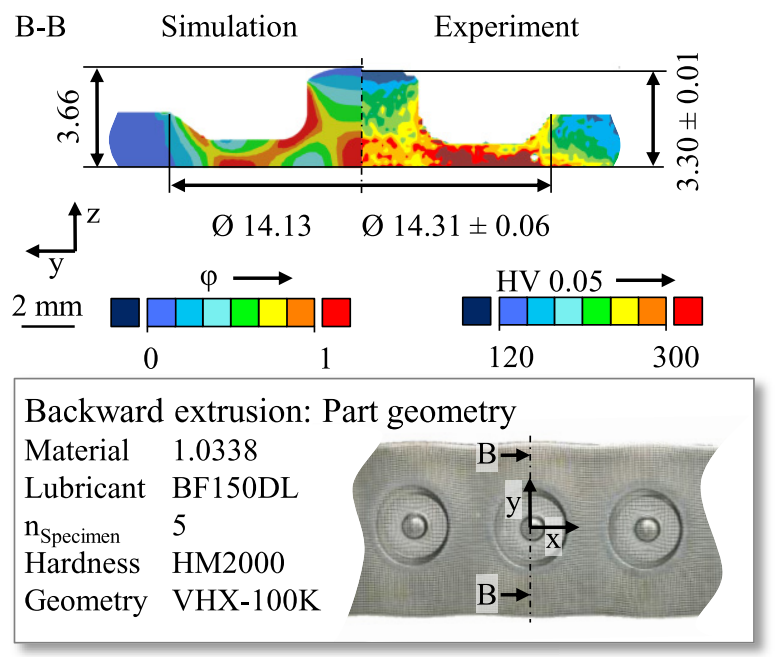

Fig. 6. Comparison of numerically and experimentally evaluated component properties in backward extrusion.

a diameter of $14 \mathrm{~mm}$ by a local mesh refinement presenting a maximum edge length of $0.075 \mathrm{~mm}$ (Fig. 4). For considering the influence of the forming of the previous component, two components per process are simulated successively and the second part is evaluated.

\subsubsection{Validation}

To assess the validity of the applied process models, they must be evaluated by comparing them with experimental results [24]. For this purpose, components are produced, applying both forming processes (Figs. 5 and 6), and subsequently compared with the simulation regarding component and process specific target values. In the lateral extrusion process, the parts are compared qualitatively and quantitatively in Figure 5.

The optical measurement of the component diameter in Y-orientation with a VHX-100K from Keyence shows a diameter of $13.73 \pm 0.08 \mathrm{~mm}$. The simulation model reproduces the experimental value with a deviation of $0.19 \mathrm{~mm}$ in good agreement. The experimentally determined diameter deviates by $2.63 \mathrm{~mm}$ compared to the targeted diameter of $11.1 \mathrm{~mm}$ (Fig. 2). This is due to a material flow out of the area of the functional element, which in analyzed in detail in Figure 8. The simulation confirms the difference between the actual and the targeted diameter. In addition to the quantitative comparison, a qualitative comparison of the mechanical component properties is conducted. For this purpose, the microhardness distribution is determined according to Vickers by ISO 14577-1 [29] with the HM2000 from Fischer on a section in the $\mathrm{Y}-\mathrm{Z}$ plane. Since the numerically determined true strain distribution correlates with the hardness due to strain hardening [30], these target values are appropriate for an indirect comparison between simulation and experiment [28]. Both, the distribution of the target values and the location of the maximum values, are identical and thus prove that the simulation is suitable for reproducing the mechanical properties of the laterally extruded parts. The same procedure is applied for comparing simulation and experiment in backward extrusion in Figure 6.

In backward extrusion the deviations between the experimentally determined Y-diameter of $14.36 \pm 0.06 \mathrm{~mm}$ and the numerically diameter of $14.13 \mathrm{~mm}$ are low and show a good agreement of simulation and experiment. Both diameters are wider than the targeted diameter of $12.0 \mathrm{~mm}$ (Fig. 2). In addition, the experimentally and numerically determined pin heights of $3.30 \pm 0.01 \mathrm{~mm}$ and $3.66 \mathrm{~mm}$ reveal a reduced component height. The targeted pin height of $8.40 \mathrm{~mm}$ is not achieved. Consequently, the simulation reproduces the dimensional deviations from the targeted geometry regarding the functional element correctly. The cause of the deviation is an uncontrolled material flow out of the functional element. This is due to local strain-induced strength gradients. Such a material flow is characteristic for SBMF and also occurs during extrusion of pre-cut blanks [11]. Besides the component geometry, a good agreement between simulation and experiment can also be observed with regard to the microhardness and true strain distribution.

For the validation of the simulation models, both workpiece- and process-specific target values must be compared [24]. Therefore, the process forces are compared in Figure 7. These are measured experimentally with a piezoelectric load cell 9106A from Kistler AG.

The numerically determined forces are in both processes during the first 30\% higher than the experimental values. This is due to the fact that in the experiments during the first $30 \%$ of the processes gaps between the different components of the tool system are closed due to the application of a load. Thus, the distance measured on the tool system overestimates the performed movement of the die. In backward extrusion the experimental values afterwards corresponds closely to the simulation. The experimentally determined maximum force of $132.7 \pm 0.4 \mathrm{kN}$ deviates by $2.5 \%$ from the numerically analyzed value. In lateral extrusion, both the experimentally and numerically determined maximum forces are higher than in backward extrusion. This is due to the larger displacement of the material out of the forming area due to the absence of a cavity 


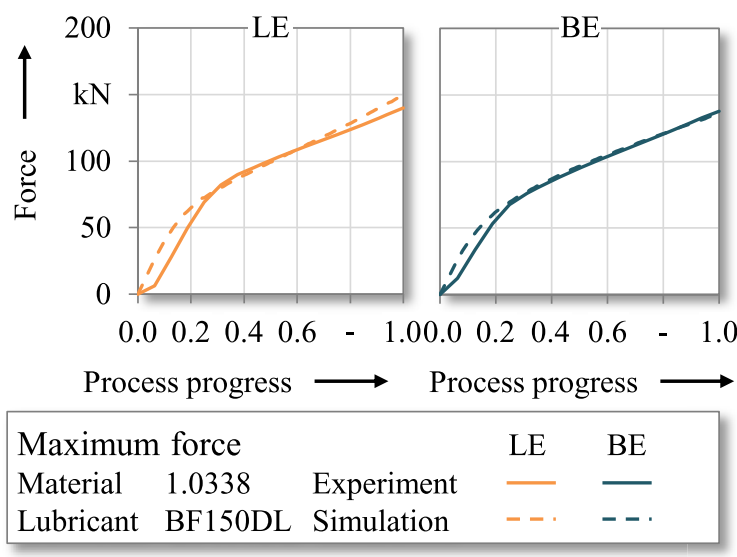

Fig. 7. Comparison of experimental and numerical forming forces in lateral (LE) and backward extrusion (BE).

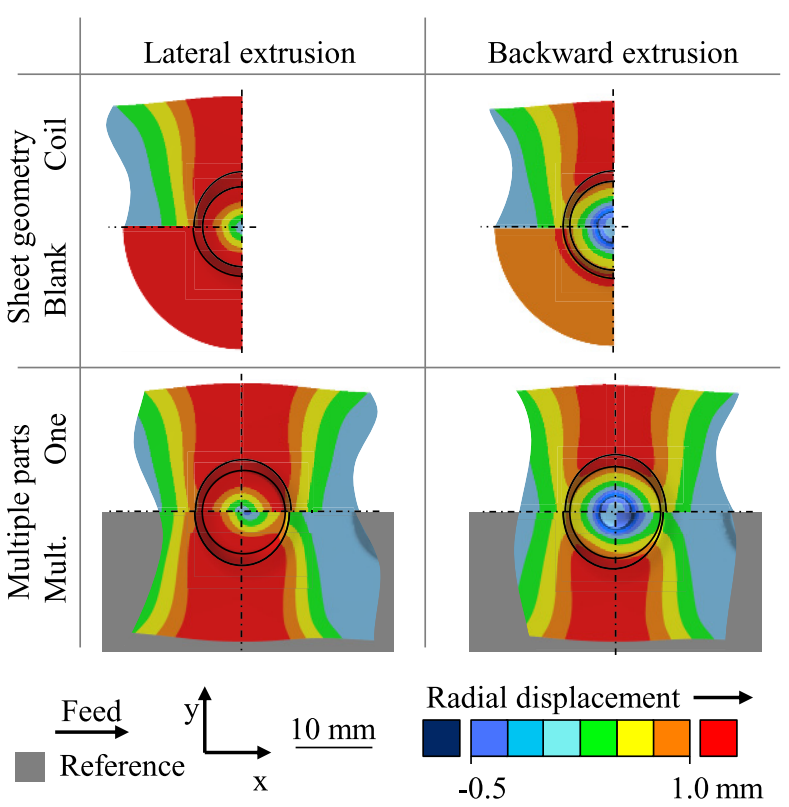

Fig. 8. Material flow in lateral and backward extrusion.

(Fig. 8). The experimentally determined maximal forming force of $138.6 \pm 0.7 \mathrm{kN}$ deviates by $7.8 \%$ from the simulation. This difference is due to the complex tribological loads of sheet bulk metal forming [4], which can only be represented numerically with limited accuracy [11]. In lateral extrusion higher contact pressures occur at the die due to higher forming forces with an approximately identical contact area. Thus, a wider range of tribological loads occurs simultaneously over the entire tool system compared to backward extrusion. Higher, but acceptable, deviations of the maximum process force than in backwards extrusion are resulting.

Overall, due to the agreement of workpiece- and process-specific values between the experiments and the simulation (Figs. 5 until 7), the virtual process models can be applied for the following analyses of the material flow as well as material flow-controlling measures.

\section{Material flow characteristics}

Within the scope of the validation of the simulations, a reduced geometrical accuracy of the components due to an uncontrolled material flow out of the functional elements, which is characteristic for SBMF, was determined in both processes. In addition, in both processes an unequal material flow in different directions can be observed at the edges of the manufactured components (Figs. 5 and 6). This anisotropic forming of the components represents a central difference to the SBMF of pre-cut blanks and is investigated in Figure 8 on the basis of numerically determined radial displacements. In the reference state the forming of multiple components from the coil - an unequal radial displacement occurs in both processes in the area adjacent to the functional elements. This radial displacement is partly due to the material flow out of the area of the functional elements caused by forming induced strain gradients (Figs. 5 and 6). Also, this material flow is more pronounced in lateral than in backward extrusion, since in this process, the entire formed volume is displaced outwards and does not partially form the pin. Additionally, in both processes, the radial displacement is anisotropic. Perpendicular to the feed direction it is on a higher level than parallel. Furthermore, it is higher against feed direction than in feed orientation.

The forming processes are adapted in Figure 8 to determine the causes for the anisotropic material flow. To analyze the cause of the unequal radial displacement in and perpendicular to the feed direction, the sheet geometry is varied. When forming a round blank, the radial displacement in both processes is rotationally symmetrical, whereby, when forming a part from a coil section, a higher radial displacement occurs perpendicular to the feed direction than parallel. This is due to the unequal supporting effect against a material flow out of the area of the functional elements. In the case of the circular blank, the distance from the part center to the edges and thus the supporting effect is the same in all directions. In contrast, when forming a coil, it varies and rises parallel to the coil direction. Consequently, the supporting effect also increases due to additional friction caused by a larger contact area between tool and workpiece as well as additional material with resistance against deformation. For the analysis of the causes of the unequal radial displacement in and against feed direction in both processes one, as well as multiple parts from one coil section are formed When forming only one component, the radial displacement in and against the feed direction is the same (Fig. 8). Consequently, the anisotropic material flow in and against the feed direction is due to the forming of multiple components from one coil section. It is explained by the local strain hardening of the coil by the forming of the previous part which can be seen in Figure 9. This reduces the material flow in feed direction.

The unequal forming of the components identified in Figures 5 and 6 can therefore be explained in both processes by the anisotropic material flow caused by the forming of several components from one coil as well as the sheet geometry. This represents a fundamental difference regarding the material flow to the forming of pre-cut 


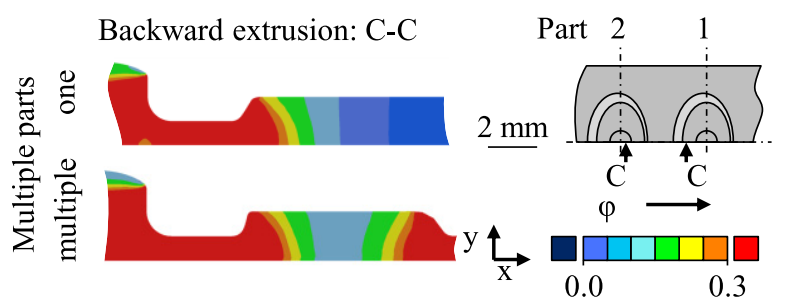

Fig. 9. Influence of the forming of one or multiple parts from a coil section on the true strain in backward extrusion.

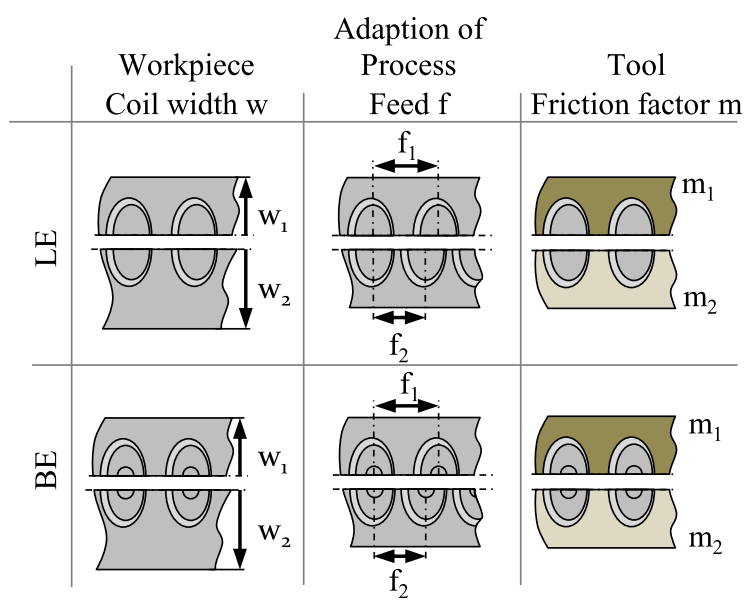

Fig. 10. Investigated material flow-controlling measures.

blanks and, in addition to the reduced die filling of the functional elements, is one of the forming limits which are to be extended by material flow controlling measures in the following.

\section{Analysis of measures}

Based on the challenges regarding the partly uncontrolled and anisotropic material flow when extruding parts from coil, measures for the improvement of the components' geometrical accuracy shall be investigated. These adaptions are divided into workpiece-, process- and tool-specific measures shown in Figure 10.

In SBMF of pre-cut blanks, there are numerous approaches for extending the forming limits. Workpiecesided measures are, for example, the usage of blanks with a locally adapted sheet thickness distribution [25] or locally adapted topographies for controlling the material flow by friction [31]. These approaches can only be implemented to a limited extent when manufacturing from coil. However, Figure 8 indicates that the sheet geometry influences the material flow. Consequently, a material flow control by adapting the coil width is being investigated within the scope of this research. A process-specific measure in SBMF of pre-cut blanks is the superimposition of the punch movement with a low-frequent oscillation [32]. The oscillations are induced by the control of the applied servo press and improve the geometrical accuracy of the formed parts. This is not possible when manufacturing from coil

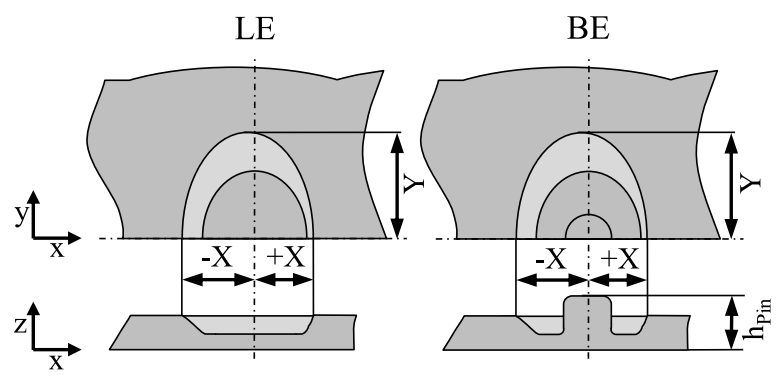

Fig. 11. Target values for the analysis of the component geometry in lateral and backward extrusion.

with a high-speed press. However, it was shown in Figure 8 that the forming of the previous component influences the material flow. Consequently, it is necessary to investigate whether the material flow can be influenced by an adaption of the feed width, which can be adapted to a limited extent when using a high-speed press. Another measure is the usage of modified tool surfaces to control the material flow by local adaptions of friction [11]. This can also be realized in a production from coil. Within the scope of the investigations, it is examined to which extent the material flow out of the area of the functional elements can be controlled by a local adjustment of the friction through an adaptation of the tool surface.

In a first step, the presented measures are investigated numerically with regard to their influence on the component geometry and the maximum forming force. Afterwards, the findings are experimentally verified with variants with numerically identified parameters. Due to the anisotropic material flow, which is irregular in all directions, the distance from the component centers to the edges in $+\mathrm{X}-,-\mathrm{X}-$ and $\mathrm{Y}$-direction is defined as a target value in Figure 11. In order to increase the comparability between the processes, these radii are referred relatively to the targeted radii of $5.55 \mathrm{~mm}$ in lateral and $6.00 \mathrm{~mm}$ in backward extrusion. As a further target value, the pin height is analyzed, to evaluate the geometrical accuracy of the pin.

\subsection{Numerical investigations of measures}

\subsubsection{Workpiece-sided measure}

As a workpiece-sided approach for a material flow control, the width of the coil is varied from $20 \mathrm{~mm}$ to $100 \mathrm{~mm}$. The influence on the geometry is shown in Figure 12.

By increasing the width of the coil, the sheet geometryrelated high Y-radius in lateral and backward extrusion (Fig. 8) decreases from 1.35 to 1.02 and 1.28 to 1.05 , respectively. The reason for this is the decreasing material flow out of the area of the functional elements perpendicular to the feed direction. This is due to the supporting effect of the additional material caused by the higher friction as a result of the larger contact surface to the tool as well as the resistance to deformation of the additional material. The reduced material flow out of the area of the functional elements also reduces the radii in -X-orientation in both processes and rises the height of the pin in backward extrusion from $3.06 \mathrm{~mm}$ to $5.48 \mathrm{~mm}$. The radius 

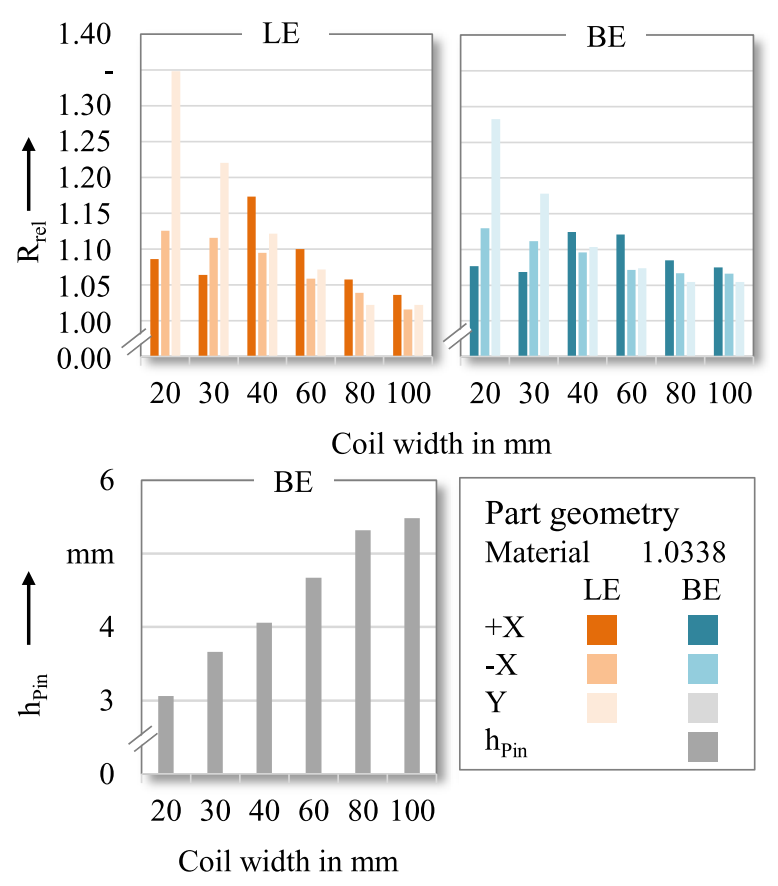

Fig. 12. Influence of the coil width on the part geometry.

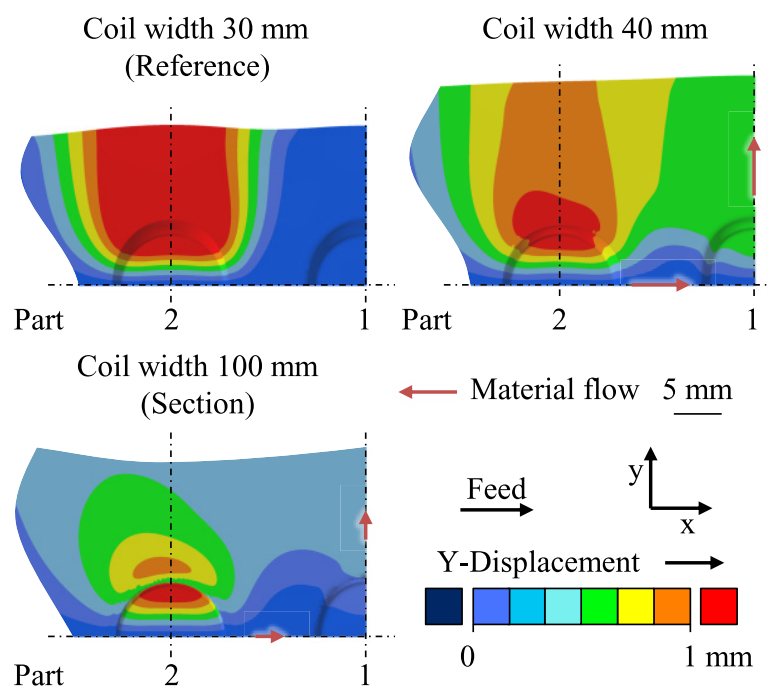

Fig. 13. Influence of the coil width on the Y-displacement in lateral extrusion.

in $+\mathrm{X}$-orientation reaches a maximum of 1.17 (LE) and 1.12 (BE) for a coil width of $40 \mathrm{~mm}$. To analyze the causality, Figure 13 shows the Y-displacement in lateral extrusion for different coil widths.

The displacement figures of the second stroke confirm that by increasing the coil width due to the additional supporting effect, the material flow perpendicular to the feed direction decreases. For the reference coil width of $30 \mathrm{~mm}$, no Y-displacement of the first part, which is caused during the forming of the second part, is visible. In contrast, for a coil width of $40 \mathrm{~mm}$, the forming of a second component causes the first component to be

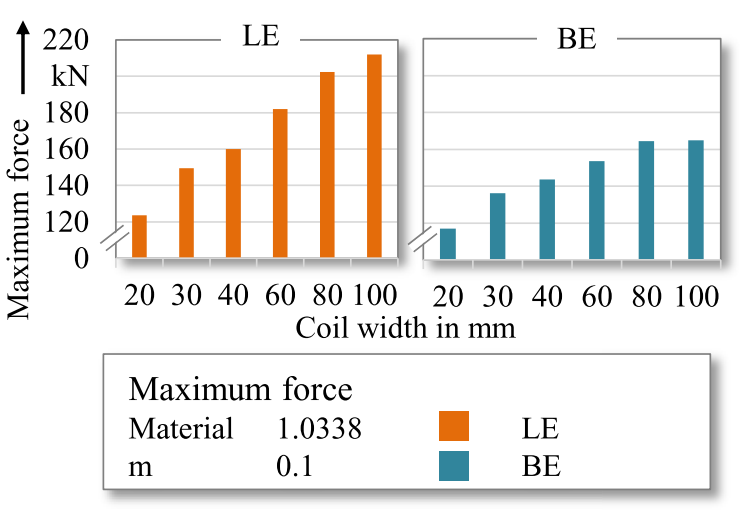

Fig. 14. Influence of the coil width on the maximum forming forces.

compressed elliptically in X-direction and stretched in Y-direction. This is due to the reduced material flow in Y-direction of the second part. Instead, the material flows in $+\mathrm{X}$-direction, inducing the maximum $+\mathrm{X}$-radius at a coil width of $40 \mathrm{~mm}$ (Fig. 12) as well as the deformation of the first part. When the coil width is further increased to $100 \mathrm{~mm}$, the deformation of the first component through forming of the second part in Y-direction is reduced due to the supporting effect of the higher coil width, which also affects the first part. This lowers the deformation of the first part in X-direction and consequently the material flow from the second component into the first part, resulting in a low $+\mathrm{X}$-radius.

To plausibilize the influence of the coil width on the material flow, Figure 14 shows the maximum forming forces for different coil widths.

By increasing the coil width, the maximum forming force in lateral and backward extrusion increases continuously from $123.6 \mathrm{kN}$ to $211.9 \mathrm{kN}$ and from $117.1 \mathrm{kN}$ to $164.8 \mathrm{kN}$. This is due the rises of the resistance against the material flow out of the area of the functional elements when increasing the coil width, which is numerically proven by a reduced radial displacement (Fig. 13). In lateral extrusion, the entire material volume is displaced outwards, whereas in backward extrusion, a part flows into the cavity of the die to form the pin (Fig. 8). Consequently, a change in the resistance against a material flow out of the area of the functional elements has a higher influence on the maximum forming force in lateral than in backward extrusion. This induces the difference in the magnitude of the increase between the processes.

\subsubsection{Process-sided measure}

To investigate the influence of the feed width on the process result, it is increased in four steps from a minimum value of $15 \mathrm{~mm}$ to $30 \mathrm{~mm}$. In addition, only one part per coil section is formed as an extreme value, see Figure 15.

In lateral extrusion, no significant influence of the feed width on the radius in -X- or Y-orientation is numerically determined. Thus, these are approximately constant. In backward extrusion, both radii are at a lower, but also approximately constant level. The radius in $+\mathrm{X}$-direction, 


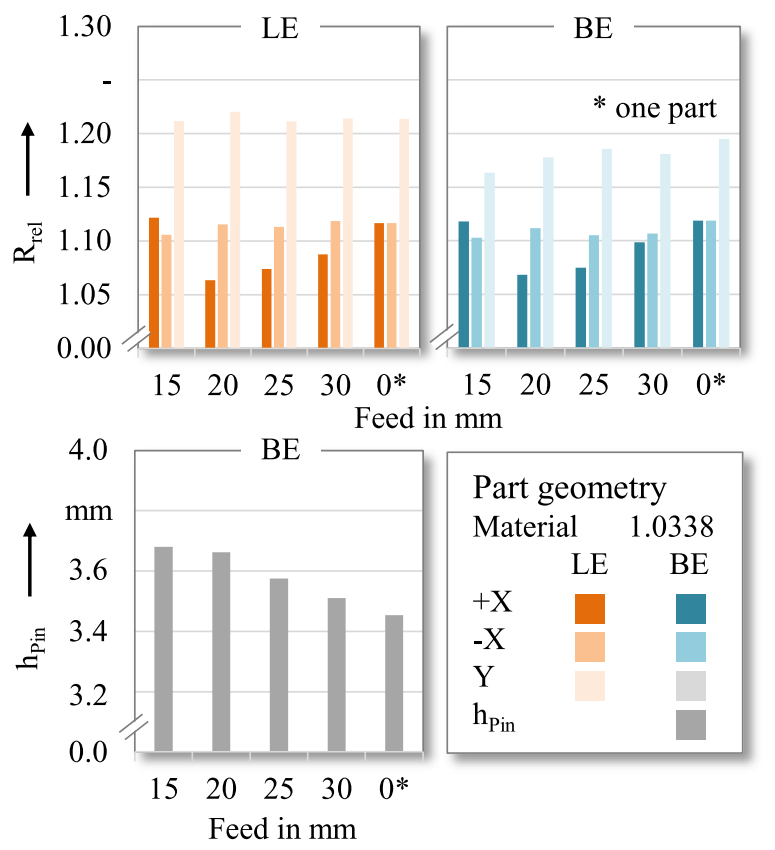

Fig. 15. Influence of the feed width on the part geometry.

however, is influenced by the feed width in both processes. In lateral extrusion, it decreases from 1.12 to 1.06 when the feed is increased from $15 \mathrm{~mm}$ to $20 \mathrm{~mm}$ (reference) and then rises continuously up to 1.12 when forming only one component per coil section. A comparable behavior occurs during backward extrusion. The reason for the increase of the $+\mathrm{X}$-radius with an enlargement of the feed distance starting from $20 \mathrm{~mm}$ is the rising distance between the components and the associated decrease of the influence of local strain hardening caused by the forming of the previous part. The anisotropic material flow in $+\mathrm{X}-$ and -X-direction is consequently reduced by increasing the feed width, but the unequal material flow in and perpendicular to the feed direction remains. The increase of the radius in $+\mathrm{X}$-direction with a reduction of the feed width from $20 \mathrm{~mm}$ (reference) to $15 \mathrm{~mm}$ in both processes cannot be explained by the influence of the local prehardening and is examined in detail in Figure 16. Besides, the feed width influences the pin. By increasing the feed width from $20 \mathrm{~mm}$ on, the pin height decreases continuously from $3.66 \mathrm{~mm}$ to $3.45 \mathrm{~mm}$. This reduction is due to the increased material flow in $+\mathrm{X}$-direction and the resulting lower material flow into the die cavity.

In order to investigate the cause of the rising $+\mathrm{X}$-radius when reducing the feed width from $20 \mathrm{~mm}$ to $15 \mathrm{~mm}$, Figure 16 shows the true strain distribution exemplary for backward extrusion before and after forming. At a feed width of $20 \mathrm{~mm}$ (reference), the first part is not affected by the forming of the second part. In contrast, at a feed width of $15 \mathrm{~mm}$, the -X-radius of the first part is reduced because the supporting effect of the material between the parts is not sufficient to prevent material flow from the second into the first part. Consequently, the $+\mathrm{X}$-radius of the second component is increased. To check the plausibility of the identified influences of the feed on the component

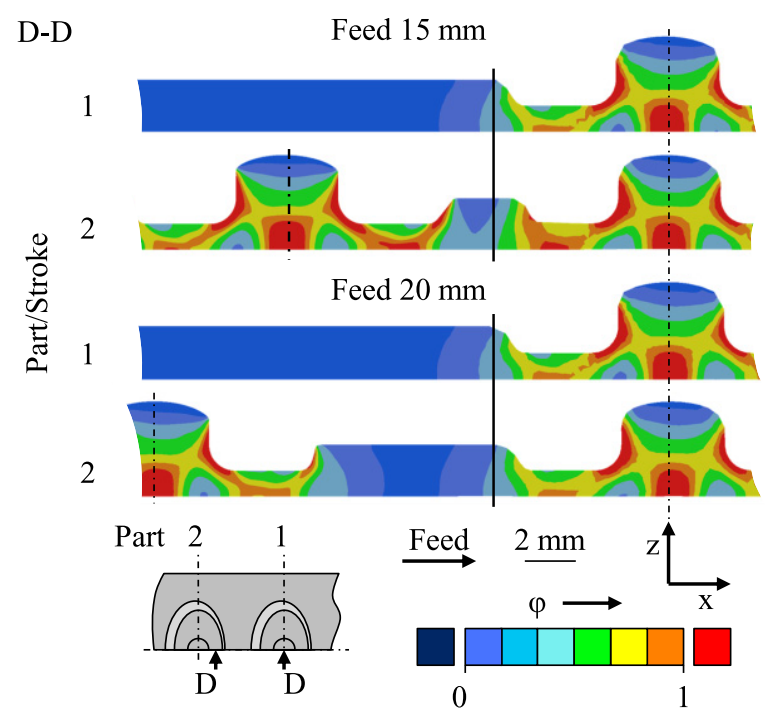

Fig. 16. Influence of the feed width on the true strain distribution in backward extrusion.

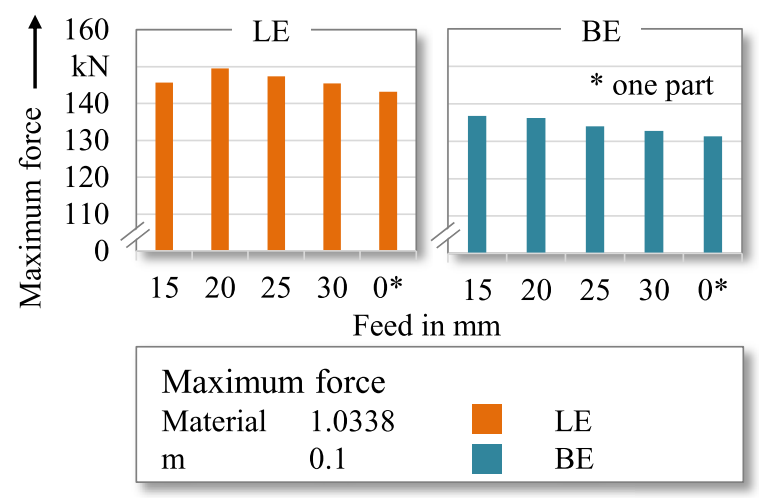

Fig. 17. Influence of the feed width on the maximum forming forces.

geometry, the maximum forming forces are shown in Figure 17.

In both lateral and backward extrusion, an increase of feed width starting from $20 \mathrm{~mm}$ (reference) results in a reduction of the maximum forming forces from $149.5 \mathrm{kN}$ to $143.2 \mathrm{kN}$ and from $136.2 \mathrm{kN}$ to $131.3 \mathrm{kN}$. The reduction confirms the lower influence of local pre-hardening induced by the forming of the previous component. A reduction of the feed width to $15 \mathrm{~mm}$ reduces the maximum forming force to $145.7 \mathrm{kN}$ in lateral extrusion. This is due to the lower resistance to a material flow out of the area of the functional element in feed direction caused by the material flow into the previous component. In backward extrusion, however, the forming force is approximately constant when the feed width is reduced to $15 \mathrm{~mm}$. A reduction in forming force occurs due to a material flow into the previous part. It is lower than in lateral extrusion, since part of the material flows into the die cavity and forms a slightly higher pin (Fig. 15). But due to the more pronounced material flow out of the $+\mathrm{X}$-half and into the die cavity, 

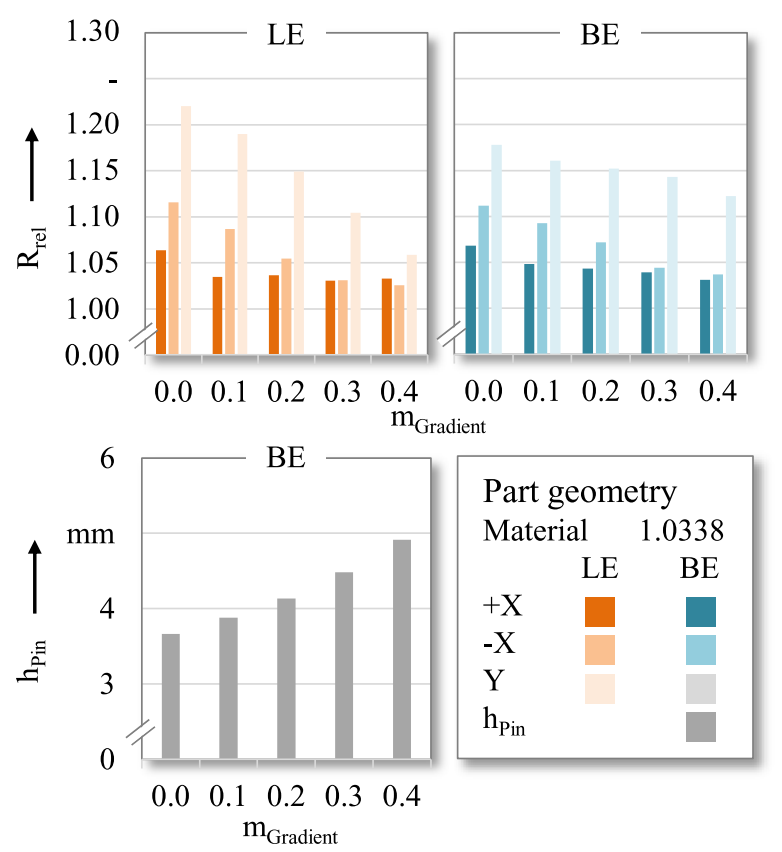

Fig. 18. Influence of the friction gradient on the part geometry.

the maximal true strain in the area where the die penetrated the sheet rises form $0.971 \pm 0.003$ (feed $20 \mathrm{~mm}$ ) to $1.207 \pm 0.004$ (feed $15 \mathrm{~mm}$ ) as can be seen in Figure 16. This, in turn with the correlation of true strain and true stress, causes an increase in the forming force and simultaneously compensates the decrease in forming force due to the material flow into the previous part.

\subsubsection{Tool-sided measure}

As a tool-sided measure, a local adjustment of friction for a material flow control is investigated. Since in both processes an undesired material flow out of the area of the functional elements was identified worsening the geometrical accuracy (Fig. 8), it is analyzed whether an increase of the friction at the blankholder reduces this effect. The friction factor at the die is constant with 0.1 . The influence of different friction factor gradients up to a value of 0.4 is researched in Figure 18. 0.4 is chosen as a maximum value, as this represents the highest gradient that can be experimentally realized by adapting the tool surface [33].

In both processes, an increase of the friction factor gradient causes a significant decrease in the relative radii. In lateral and backward extrusion, the Y-radii decrease continuously from 1.22 to 1.06 and from 1.18 to 1.12 . The $+\mathrm{X}$ - and $-\mathrm{X}$-radii also decline and the anisotropy of the material flow is reduced. The reason for this is that the material flow from the area of the functional elements is decreased due to the locally higher friction. Thus, the forming of the edges is improved. In backward extrusion, the height of the pin rises from $3.66 \mathrm{~mm}$ to $4.91 \mathrm{~mm}$ due to the reduced volume of the material flow out of the area of the functional element. Since in lateral extrusion the entire volume of the formed material is displaced under the

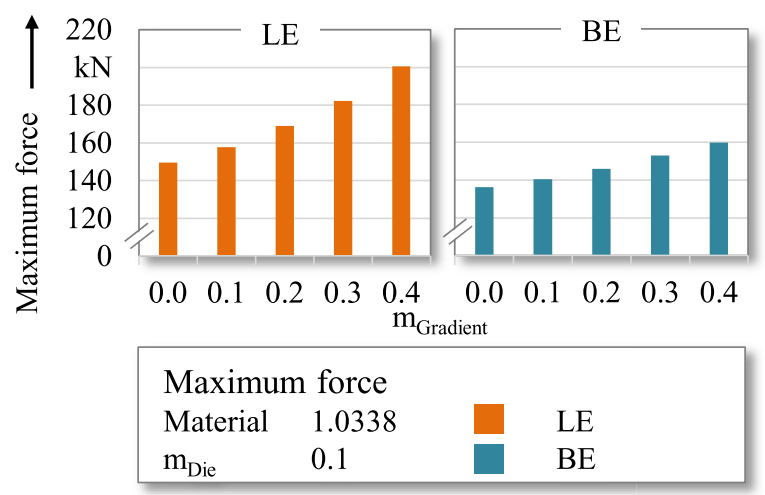

Fig. 19. Influence of the friction gradient on the maximal forming force.

blankholder, whereas in backward extrusion a part flows into the die cavity, in lateral extrusion the friction adjustment on the blankholder influences the process more strongly. To verify the plausibility of this, the maximum forming forces are analyzed in Figure 19.

By increasing the friction factor on the blankholder, the maximum forming forces in lateral and backward extrusion increase from $149.5 \mathrm{kN}$ to $200.6 \mathrm{kN}$ and from $136.2 \mathrm{kN}$ to $159.9 \mathrm{kN}$, respectively. This confirms the higher resistance against a material flow out of the area of the functional elements as a result of the locally higher friction. The increase is more pronounced in lateral extrusion, as the entire material volume is displaced outwards into the area of higher friction, whereas in backward extrusion, a part of the formed material volume flows into the die cavity with a constantly low friction factor of 0.1 .

\subsection{Experimental verification of measures}

For the verification of the numerical results regarding the material flow, the measures are experimentally implemented for selected variants. Firstly, the effects of the coil width on the component geometry are verified by varying it in three steps from $20 \mathrm{~mm}$ to $30 \mathrm{~mm}$, see Figure 20 . A further increase is not possible due to the applied tool system.

By increasing the coil width from $20 \mathrm{~mm}$ to $30 \mathrm{~mm}$, the Y-radius in lateral and backward extrusion is reduced from $1.39 \pm 0.01$ to $1.24 \pm 0.01$ and from $1.30 \pm 0.01$ to $1.19 \pm 0.01$. This confirms the numerically identified correlation that an increase of the coil width reduces the Y-radius due to a decrease of the material flow out of the functional element in Y-orientation. In addition, the smaller material flow out of the functional element is confirmed by the increase of the height of the pin from $2.79 \pm 0.01 \mathrm{~mm}$ to $3.30 \pm 0.01 \mathrm{~mm}$.

To verify the influence of the feed width on the part geometry, the feed is varied from $20 \mathrm{~mm}$ to $30 \mathrm{~mm}$ in Figure 21. In addition, as in the numerical investigations, a single part on one coil section is formed as an extreme value without the influence of a previous forming operation. The feed width is not reduced to $15 \mathrm{~mm}$, because numerical analysis has shown that this deforms the previous part 


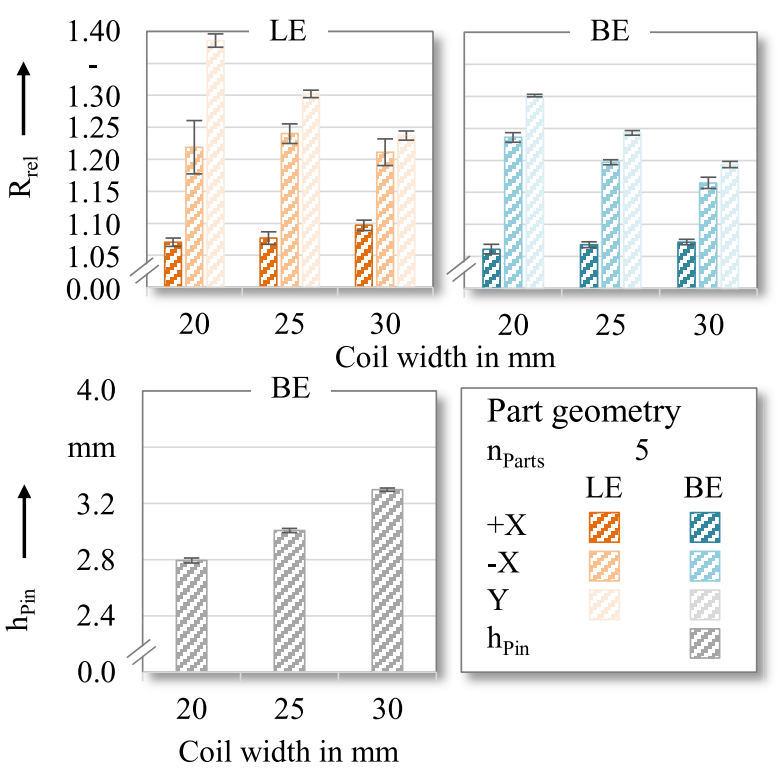

Fig. 20. Experimental verification of the influence of the coil width on the component geometry.

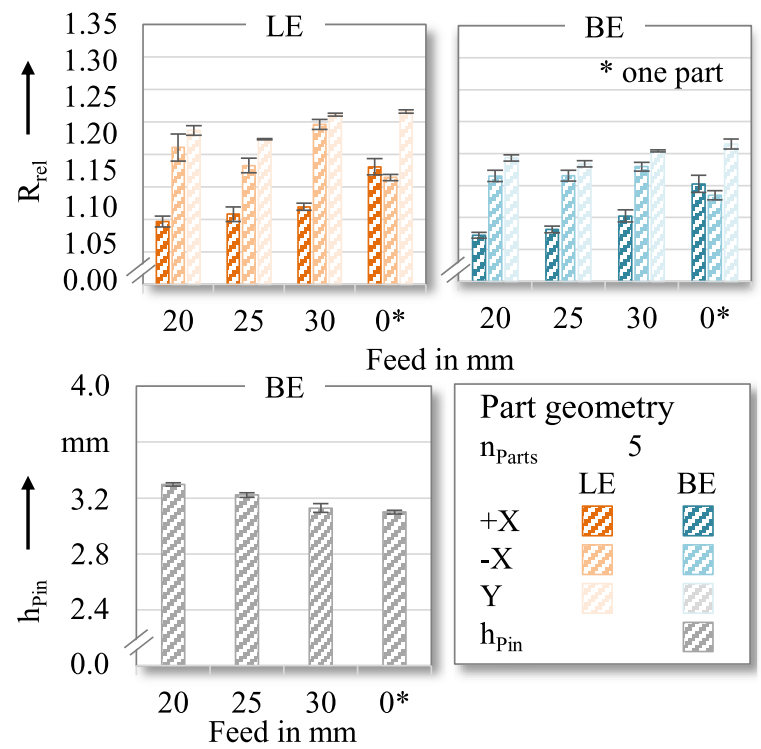

Fig. 21. Experimental verification of the influence of the feed width on the component geometry.

(Fig. 16), which impedes the experimental production from coil.

The radius in $+\mathrm{X}$-orientation increases in lateral and backward extrusion from $1.10 \pm 0.01$ to $1.18 \pm 0.01$ and from $1.07 \pm 0.01$ to $1.15 \pm 0.01$. When forming only one part from a coil section, the $-\mathrm{X}$-radius declines due to the increasing material flow in $+\mathrm{X}$-orientation. The experiments confirm that by increasing the feed width, the anisotropic material flow in and against feed direction is reduced due to the lower influence of the local prehardening induced by the forming of the previous component. In addition, this causes a decrease in pin height from $3.30 \pm 0.01 \mathrm{~mm}$ to $3.10 \pm 0.01 \mathrm{~mm}$.

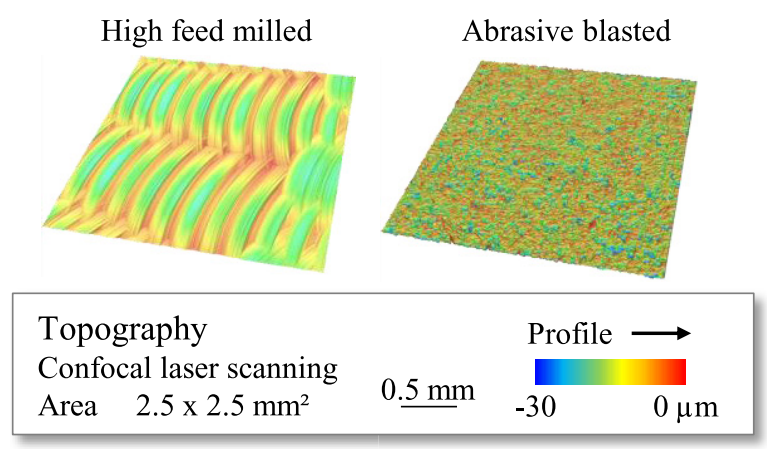

Fig. 22. Applied tool surfaces for the experimental investigation of the influence of tailored surfaces.

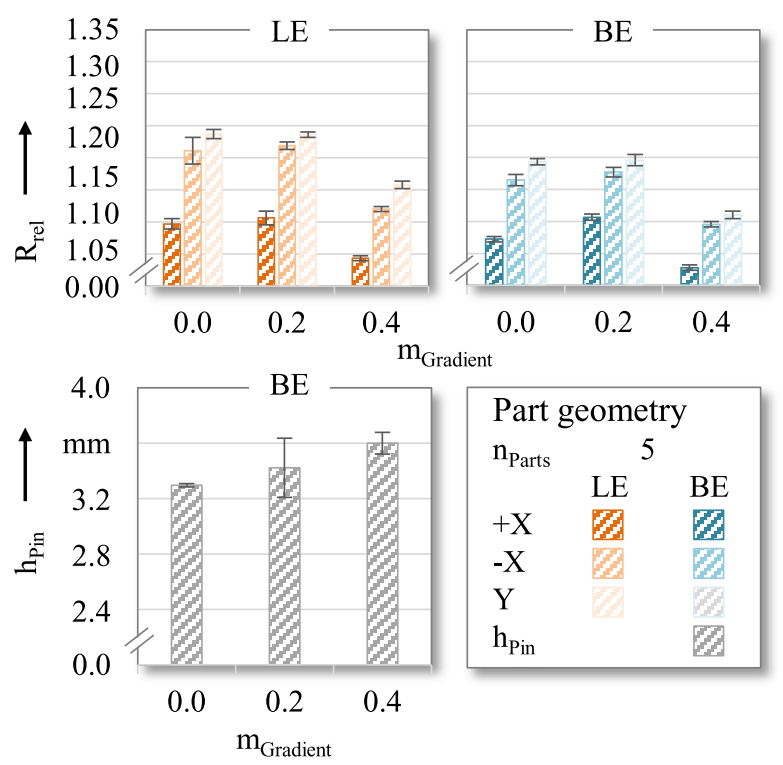

Fig. 23. Experimental verification of the influence of tailored surfaces on the component geometry.

In order to verify the influence of a local friction adjustment by modified tool surfaces, the friction on the blankholder is locally increased by tailored surfaces. The modifications shown in Figure 22 are applied for this purpose.

Blankholders with a high-feed milled surface are used. This modification is described in detail in [34] and causes a friction factor gradient to the die of approximately 0.2 . In order to investigate the influence of a higher gradient, abrasive blasted blankholders are applied as well. This surface modification investigated in [33] causes a friction factor gradient of approximately 0.4. Both surface modifications increase the friction due to their rough topography and the resulting mechanical interlocking of tool and workpiece roughness peaks. The influence of these modifications on the workpiece geometry is analyzed in Figure 23.

A friction factor gradient of 0.4 causes a significant reduction of the radii in both lateral and backward extrusion. This is a result of a friction-related reduction of 
the undesired material flow oriented away from the functional elements. In contrast, a gradient of 0.2 is in the experiments too low in both processes to reduce the anisotropic material flow and radii. With regard to the pin height, however, all friction factor gradients result in an improvement when forming the functional element. It is continuously increased from $3.30 \pm 0.1 \mathrm{~mm}$ to $3.42 \pm 0.21 \mathrm{~mm}$ and finally, up to $3.60 \pm 0.08 \mathrm{~mm}$.

The experiments confirm the numerically identified influences of the workpiece-, process- and tool-sided measures on the material flow. Any differences in the level of the numerically and experimentally investigated values are due to the complex tribological conditions of SBMF [4], which can only be represented numerically with limited accuracy [11].

\section{Derivation of conclusions}

Based on the investigation of the material flow and the combined numerical-experimental analysis of material flow-controlling measures, findings are concluded and material flow-controlling approaches are evaluated.

The uncontrolled and anisotropic material flow represents a central challenge for SBMF components from coil. As in SBMF of pre-cut blanks, the geometrical accuracy of the parts in both investigated processes is limited due to the material flow oriented away from the functional elements (Figs. 5 and 6). One reason for this are forming-induced local strain gradients. A difference to SBMF of pre-cut blanks is the anisotropic material flow, which causes an unequal forming of the components (Fig. 8). The different material flow perpendicular and parallel to the coil feed direction is due to the sheet geometry. The coil causes an unequal supporting effect in each directions. Perpendicular to the feed direction, the distance from the forming zone to the edge and thus the supporting effect is the smallest, making the material flow towards the outside the highest. In addition, an anisotropic material flow occurs in and against the feed direction. It is caused by the forming of multiple parts form one coil (Fig. 8). The anisotropy is affected by the local pre-hardening of the coil, induced by the forming of the previous part. In order to use the advantages of SBMF of components from coil, measures are being researched to counteract both, the reduced die filling of the functional elements and the anisotropic material flow. These are evaluated in Figure 24.

In both investigated processes, an increase in coil width results in a significant decrease in the anisotropic material flow perpendicular and parallel to the feed direction (Fig. 12). The reason for this is the additional material perpendicular to the feed direction, which reduces the material flow out of the functional elements due to a higher supporting effect in this direction. The supporting effect is a result of higher friction caused by the larger contact area and the resistance of the additional material to deformation. By reducing the material flow perpendicular to the feed direction, the material flow oriented away from the functional elements is reduced and consequently, the pin height of the components increases. The higher resistance to a material flow away from the functional elements also

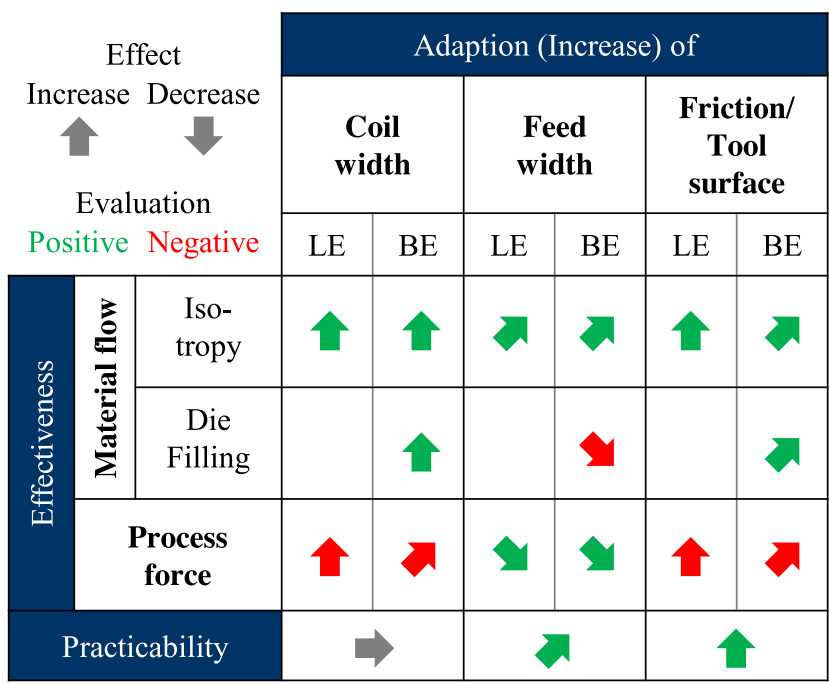

Fig. 24. Evaluation of investigated measures.

causes an increase in the required forming force in both processes (Fig. 14). This is more pronounced in lateral than in backward extrusion, since in this process, the inhibited material flow to the outside cannot flow into a die cavity. When evaluating the practicability of this approach, it must be considered that a substantial increase in the width of the coil is necessary to reduce the anisotropic material flow. Consequently, the material efficiency of the processes decreases. Furthermore, it was proven that for a width of $40 \mathrm{~mm}$, the geometrical accuracy of the previous component is negatively influenced by a material flow into it (Fig. 13).

The adaptation of the feed width is, in contrast to the adaptation of the coil width, not capable of compensating the anisotropic material flow in and perpendicular to the feed direction. However, it reduces the unequal material flow in and against the feed direction (Fig. 15). The reason for this is that a higher distance between the components reduces the influence of the local pre-hardening of the coil induced by forming the previous component. Consequently, the material flow in $+\mathrm{X}$ - and $-\mathrm{X}$-direction assimilates. Nonetheless, this also reduces the pin height. On the positive side, the higher feed width in both processes lowers the required forming force (Fig. 17). Regarding the practicability of the measure, it must be evaluated that an increase in feed width reduces the material efficiency. Nevertheless, a reduction of the feed width can be applied to improve the forming of the pin by reducing the material flow out of the area of the functional element in $+\mathrm{X}$-direction and simultaneously increasing material efficiency. Still, the increasing anisotropy of the material flow as well as the negative influence on the geometrical accuracy of the previous component must be taken into account (Fig. 16).

In both processes, the local adaptation of the friction by modifying the blankholder surface is the only measure that reduces both the anisotropic material flow in and against the feed direction as well as perpendicular and parallel to the coil (Fig. 18). The reason for this is the decrease of the material flow oriented away from the functional elements 
by a locally higher friction in the area adjacent to the functional elements. This also increases the height of the pin in backward extrusion (Fig. 18). At the same time, an increase in the forming forces results (Fig. 19), which is more pronounced in lateral than in backward extrusion, since in lateral extrusion, there is no cavity in the die where the outwardly inhibited material flow could flow. The practical applicability of the approach can be rated as high, since it neither extends the process chain nor reduces material efficiency.

\section{Summary and outlook}

The extrusion of components from the coil enables the combination of the advantages of SBMF in terms of lightweight design by functional integrated components with those of a production from the coil in terms of higher output quantities due to shorter cycle times. Currently, the investigations of SBMF mainly focuses on pre-cut blanks. To benefit from the advantages of SBMF parts from the coil, two processes were set up and numerically modeled. It was shown that when SBMF components from coil, an anisotropic material flow is a further challenge additionally to the reduced geometrical accuracy of the functional elements known from the SBMF of pre-cut blanks. Numerically, the adaptation of the coil width, the feed width as well as a local friction adaptation were investigated with regard to the suitability for a material flow control. The results, verified by experiments, show that especially a local friction adjustment can reduce the undesired material flow oriented away from the functional elements as well as the anisotropic shape of the components. Hence, the forming limits when SBMF parts from coil are extended when using tailored friction systems by modified tool surfaces.

Given those facts, the functional stability of the measure is to be investigated in future research. It must be analyzed whether potential wear of the modified tool surfaces changes the effectiveness of this measure.

This research was supported by the German Research Foundation (DFG) within the scope of the Transregional Collaborative Research Centre 73 for sheet-bulk metal forming (CRC 73, Subproject C1) under grant number TRR73/3 68237143. The authors are also grateful to all laboratory assistants and students who supported the execution of this work.

\section{References}

1. J. Jeswiet, M. Geiger, U. Engel, M. Kleiner, M. Schikorra, J. Duflou, R. Neugebauer, P. Bariani, S. Bruschi, Metal forming progress since 2000, CIRP J. Manufactur. Sci. Technol. 11 (2008) 2-17

2. A.E. Tekkaya, N.B. Khalifa, G. Grzancic, R. Hölker, Forming of lightweight metal components: need for new technologies, Proc. Eng. 81 (2014) 28-37

3. M. Merklein, H. Hagenah, T. Schneider, Sheet-bulk metal forming processes - state of the art and its perspective, in Science Meets Industry, TTP, Tools and Technologies for Processing Ultra High Strength Materials, 2013, Verlag der Technischen Universität, Graz, 2013, 197-204
4. M. Merklein, J.M. Allwood, B.A. Behrens, A. Brosius, H. Hagenah, K. Kuzman, K. Mori, A.E. Tekkaya, A. Weckenmann, Bulk forming of sheet metal, CIRP Ann. Manufactur. Technol. 61 (2012) 725-745

5. K. Mori, T. Nakano, State-of-the-art of plate forging in Japan, Product. Eng. 10 (2016) 81-91

6. T. Nakano, Introduction of flow control forming (FCF) for sheet forging and new presses, in Proceedings of the International Seminar on Precision Forging, Kyoto, 2009

7. Y. Oyachi, J.M. Allwood, Characterizing the class of local metal sheet thickening processes, in 10th ICTP-International Conference on Technology of Plasticity, Düsseldorf: Steel Research International, 2011, 1025-1030

8. X.-L. Sun, X.-C. Zhuang, F.-C. Yang, Z. Zhao, Reduction of die roll height in duplex gears through a sheet-bulk metal forming method, Adv. Manufactur. 7 (2019) 42-51

9. X. Zhuang, X. Sun, H. Xiang, M. Xia, Z. Zhao, Compound deep drawing and extrusion process for the manufacture of geared drum, Int. J. Adv. Manufactur. Technol. 84 (2015) $2331-2345$

10. Z.G. Wang, K. Hirasawa, Y. Yoshikawa, K. Osakada, Forming of light-weight gear wheel by plate forging, CIRP Ann. 65 (2016) 293-296

11. F. Pilz, J. Henneberg, M. Merklein, Extension of the forming limits of extrusion processes in sheet-bulk metal forming for production of minute functional elements, Manufactur. Rev. 7 (2020) 1-12

12. S. Haage, M. Straub, A. Birkert, Umformtechnische Herstellung komplexer Karosserieteile - Auslegung von Ziehanlagen (Springer-Verlag, Berlin, 2013), 1

13. B.T. Cheok, A.Y.C. Nee, Configuration of progressive dies, Artif. Intell. Eng. Des. Anal. Manufactur. 12 (1998) $405-418$

14. K. Hayashi, Tool engineering for fineblanking and sheet metal forging complex work, J. Jpn. Soc. Technol. Plasticity 47 (2006) 554

15. L. Tajul, T. Maeno, K.-I. Mori, Successive forging of long plate having inclined cross-section, Proc. Eng. 81 (2014) $2361-2366$

16. International Cold Forging Group ICFG, General recommondations for design, manufacture and operational aspects of cold extrusion tools for steel components, in International Cold Forging Group 1967-1992 - Objectives, History Published Documents (Meisenbach, Bambergm 1992), pp. $33-58$

17. M. Merklein, A.E. Tekkaya, A. Brosius, S. Opel, J. Koch, Overview on sheet-bulk metal forming processes, in Proceedings ICTP., edited by G. Hirt, A.E. Tekkaya (Wiley-VCH, 2011) 1109-1114

18. W. Dong, C. Zhang, Q. Lin, Z. Wang, Investigation on dimple defect mechanism in solid boss forming process by plate forging, in International Conference on the Technology of Plasticity, Elsevier, 2017, 1159-1164

19. Z.G. Wang, Y. Yoshikawa, K. Osakada, A new forming method of solid bosses on a cup made by deep drawing, CIRP Ann. Manufactur. Technol. 62 (2013) 291-294

20. X.-C. Zhuang, H. Xiang, Z. Zhao, Analysis of sheet metal extrusion process using finite element method, Int. J. Autom. Comput 7 (2010) 295-302

21. S. Schlagau, W. Tobler, Stand und Entwicklungstendenzen der Feinschneidtechnik, Materialwissenschaft und Werkstofftechnik 31 (2000) 972-978 
22. H. Vierzigmann, Beitrag zur Untersuchung der tribologischen Bedingungen in der Blechmassivumformung Bereitstellung von Modellversuchen und Realisierung von Tailored Surfaces, PhD-Thesis, FAU, 2015

23. D. Gröbel, R. Schulte, P. Hildenbrand, M. Lechner, U. Engel, P. Sieczkarek, S. Wernicke, S. Gies, A.E. Tekkaya, B.A. Behrens, S. Hübner, M. Vucetic, S. Koch, M. Merklein, Manufacturing of functional elements by sheet-bulk metal forming processes, Product. Eng. 10 (2016) 63-80

24. A.E. Tekkaya, A guide for validation of FE-simulations in bulk metal forming, Arab. J. Sci. Eng. 30 (2005) 113-136

25. D. Gröbel, Herstellung von Nebenformelementen unterschiedlicher Geometrie an Blechen mittels Fließpressverfahren der Blechmassivumformung. PhD-Thesis, FAU, 2018

26. DIN Deutsches Institut für Normung e.V., DIN 50106Prüfung metallischer Werkstoffe - Druckversuch bei Raumtemperatur (Beuth-Verlag, Berlin, 2016)

27. J.E. Hockett, O.D. Sherby, Large strain deformation of polycrystalline metal at low homologous temperatures, J. Mech. Phys. Solids 23 (1975)

28. A.E. Tekkaya, P.A.F. Martins, Accuracy, reliability and validity of finite element analysis in metal forming: a user's perspective, Int. J. Comput. Aided Eng. Softw. 26 (2008) 1026-1055
29. DIN Deutsches Institut für Normung e.V., DIN EN ISO 14577-1:2015-11: Metallische Werkstoffe - Instrumentierte Eindringprüfung zur Bestimmung der Härte und anderer Werkstoffparameter - Teil 1: Prüfverfahren (Beuth-Verlag, Berlin, 2015)

30. M.P. Groover, Fundamentals of modern manufacturing: materials processes, and systems (John Wiley \& Sons, 2007)

31. M. Löffler, K. Andreas, U. Engel, R. Schulte, D. Groebel, E. Krebs, D. Freiburg, D. Biermann, D. Stangier, W. Tillmann, T. Weikert, S. Wartzack, S. Tremmel, H. Lucas, B. Denkena, M. Merklein, Tribological measures for controlling material flow in sheet-bulk metal forming, Product. Eng. 10 (2016) 459-470

32. T. Maeno, K. Mori, A. Hori, Application of load pulsation using servo press to plate forging of stainless steel parts, J. Mater. Process. Technol. 214 (2014) 1379-1387

33. J. Henneberg, H. Lucas, B. Denkena, M. Merklein, Investigation on the tribological behavior of tool-sided tailored surfaces for controlling the material flow in sheetbulk metal forming, in Proceedings of the 22nd International ESAFORM Conference on Material Forming, 2019

34. D. Freiburg, R. Aßmuth, G.R. Carballo, D. Biermann, J. Henneberg, M. Merklein, Adaption of tool surface for sheet-bulk metal forming by means of pressurized air wet abrasive jet machining, Product. Eng. 13 (2018) 71-77

Cite this article as: Johannes Henneberg, Marion Merklein, Measures for controlling the material flow when extruding sheet-bulk metal forming parts from coil, Manufacturing Rev. 7, 36 (2020) 